\title{
Trends in Gender Portrayal in the Marvel Cinematic Universe Avengers Series: A Conventional Content Analysis
}

\author{
Haley Morales ${ }^{1}$ and Daniel Olivo ${ }^{1}$ \\ ${ }^{1}$ Bergen County Technical High School, Teterboro, NJ, USA
}

\section{$\underline{\text { ABSTRACT }}$}

The Bechdel test, used to examine the frequency and portrayal of women in film, consists of three criteria - (1) a movie must represent two or more women, (2) who have names and speak to each other, (3) about anything other than a man. In order to answer the research question "Based on the Bechdel test, how does the Avengers series portray their female characters compared to their male characters?", this paper utilizes and extends beyond the Bechdel test by performing a conventional content analysis of same-gender conversations in four top-grossing superhero films - Marvel's The Avengers (2012), Avengers: Age of Ultron (2015), Avengers: Infinity War (2018), and Avengers: Endgame (2019). By combining the simplicity of the Bechdel test with a qualitative approach to code dialogue, this paper illustrates the underrepresentation of female characters and specific differences between the portrayal of men and women in modern Marvel films. While the films improved in the number of female characters and female-to-female conversations over time, there is still a small number of female-to-female conversations in these films compared to male-tomale conversations. Furthermore, while male characters rarely spoke to each other about women, female characters spoke to each other about men very often. Some common elements of dialogue for both male and female characters were worries about danger, discussions of violence, and insulting others. Implications regarding this portrayal's impact on female viewers are discussed.

\section{Introduction}

\subsection{Underrepresentation of women in film}

Extensive international quantitative research has revealed gender bias in popular films. From 2007-2012, women were heavily underrepresented both on and behind the screen; the percentage of speaking female characters in the films ranged from $28.4 \%$ to $32.8 \%$ based on the year, and $2.7 \%$ to $8 \%$ of directors of the top-grossing films were female (Smith et al., 2013). This lack of representation continues in more recent studies; Anderson and Daniels reported that even when a film had a female protagonist, the dialogue tended to be male dominated (2016). Furthermore, on the small screen, men played $60 \%$ of both protagonists and supporting roles in popular Spanish television (Alvarez-Hernandez et. al., 2015). None of the top 10 movies of 2016 had more than a $43 \%$ female speaking cast (Thomas, 2017). In the top grossing films of 2018, males were nearly twice as likely to have a speaking role in a movie and there were very few women of color in the casts (Lauzen, 2019). 


\subsection{Misrepresentation of women in media}

\subsubsection{Hypersexualization}

Women are hypersexualized in several forms of media, from papers to the big screen. In an analysis of popular magazine covers from 2012, 90\% had hypersexual images, such as the women being partially/mostly nude (Johnson, 2015). In the past, many films from the 1960s-70s used sexual images of black women in order to persuade a larger audience to watch the film; rather than making films with female characters for everyone's/women's enjoyment, these characters were often included to market towards heterosexual males (Heyde, 2007). More recent studies revealed a continuity in this trend. An analysis of top-grossing films from 2007-2012 supports Heyde's claim by concluding that female characters were heavily sexualized; about one-third of the characters analyzed wore sexually revealing attire or were partially naked in 2010 and 2012 (Smith et al., 2013). Behind the screen, women's descriptions are hypersexualized and focus solely on their appearance in many American screenplays, while male descriptions focus on their intelligence and personality (O’Meara, 2017).

Like other popular films, the Avengers series hypersexualizes its female characters through both visual and textual representations. According to Gerard and Poepsel, Black Widow, the most prominent female character of the Marvel Cinematic Universe, was written as a character to entertain the male gaze, performing actions like undressing in the backseat of a car and being a lingerie model in the past. While they acknowledged that she is sometimes portrayed as a caring and cooperative teammate, she is predominantly belittled by battling in sexually suggestive poses and outfits, furthering the appeal to the male gaze (Gerard \& Poepsel, 2018). While this study focused on one specific female character, the present study aims to find out whether other female characters in the Avengers series are sexualized through dialogue as well.

\subsubsection{Weak female portrayal in film}

Earlier research findings show that women are not only given less dialogue than men, but the actual words they speak portray them as fragile, submissive, and less important than men. The female characters studied by Alvarez-Hernandez et al. tended to lack defined objectives besides finding a relationship with a man, which were rarely acted upon, whereas male characters had several objectives that they acted upon such as becoming integrated in society, winning competitions, and partying (2015). Schofield and Mehr illustrated that cursing was a male-favored practice while women were more likely to use polite greetings and words like "please" than men, revealing that women are often submissive and lack assertion or aggression in their words (2016). An examination of Academy Award-nominated screenplays found that male characters tend to have their own independent description while women are described as possessions (O’Meara, 2017). Overall, films tend to reveal a gender bias by providing women with less significant dialogue that either does not relate to the plot or solely focuses on men, and the present study will be using the Bechdel test to explore this phenomenon in the Avengers series.

\subsection{Impact on female viewers}

These underrepresentations and weak portrayals of women are not only present in the media but have been shown to negatively impact female viewers. A 1996 study found that people were more likely to agree with statements about traditional gender roles after they viewed a stereotypical image of a woman, such as a woman cleaning her home. This revealed that stereotypical images lead to stereotypical beliefs (Lafky et. al., 1996). Similarly, Behm-Morawitz and Mastro established a connection between an increase of viewing teen movies and an increase of negative attitudes towards female friendships as well as women in general, further implying that poor portrayals can lead to poor perceptions of women (2008). Since portrayals of women in film are known to impact real-life beliefs about women, it is crucial to continue research on portrayals of women as the film industry grows. This present study aims to contribute 
to the current understanding of these portrayals in order to find whether women are potentially harmed or empowered by watching superhero films.

Studies have been conducted that reveal the impact of female portrayals in superhero films specifically. The Women's Media Center reported that young girls tend to view female characters as their top role models rather than male characters, and that female characters in sci-fi and superhero films help girls gain confidence by making them feel brave, strong, and positive (2018). Behm-Morawitz mirrored her previously mentioned 2008 study in 2015 and found a connection between participants viewing sexualized female characters in superhero films and believing less egalitarian beliefs about women's role in society; viewing the sexualized portrayals was also associated with a lower body self-esteem (Behm-Morawitz, 2015).

\subsection{The Bechdel Test}

Comic artist Alison Bechdel created a strip in the 1980s named The Rule which then kickstarted the Bechdel test (1986). It consists of three criteria - (1) a movie must represent two or more women, (2) who have names and speak to each other, (3) about anything other than a man. This test has been used by an array of studies to examine the frequency of appearance and portrayal of women in film. According to Agarwal et. al., movies that failed the Bechdel test also lacked central female characters, their female characters had less meaningful roles than male characters, they lacked meaningful relationships with both men and women, and there were fewer women in the film in general (2015). Graduates from Duke University agree, noting that the Bechdel score of a movie (1, 2, or 3) nearly perfectly correlated to the amount of female dialogue in a film (Berkman et. al., 2017). The Bechdel test, however, isn't entirely perfect for measuring the importance of women in film since it is overly simplistic and doesn't specify any other topics that female characters speak about besides men (O'Meara, 2016). Other studies recognized this and extended beyond the Bechdel test by finding the proportions of male interactions to female interactions (Micic, 2015), and performing a "Reverse Bechdel" that used the same three criteria, but regarding male characters (Kapoor et. al., 2015). Although different methods were used, these studies also reported a severe lack of female dialogue in films as well as trends of male characters holding more varied conversations than women particularly in top-grossing films.

\subsection{Present study}

Although research has been done to support that stereotypical portrayals of women exist in film as well as a lack of female importance in film, most of these studies either quantitatively examine female dialogue or qualitatively examine visual portrayals of women in film. Little research has compared female dialogue to male dialogue in depth, so the prominence and portrayal of female characters compared to the overall character portrayals in recent popular films is unknown. Furthermore, few studies have extended beyond the Bechdel test with American films, with most uses occurring in Indian and Swedish studies (Kapoor et. al., 2015; Micic, 2015). This study aims to fill these gaps by utilizing the Bechdel test as well as examining the differences between female and male same-gender conversations in one of the highest grossing film series: The Avengers series produced by Marvel Studios. Since this series has some of the globally highest grossing films, their portrayal of women reaches a substantial audience. By qualitatively observing and analyzing these films with the three criteria of the Bechdel test, the prominence of women in the films can be determined. This will be extended upon by examining and describing the different topics within female and male same-gender conversations. Since Schofield and Mehr have previously established that there are distinct differences between male and female speech, it is hypothesized that female-to-female conversations and male-to-male conversations will differ in content (2016). This review of literature led to the research question: Based on the Bechdel test, how does the Avengers series portray their female characters compared to their male characters? 


\section{Method}

\section{Sample}

With a relatively recent time frame of 2012-2019, the films from the Marvel Cinematic Universe with the word "Avengers" in the title were chosen as a sample, which made up the Avengers series. The Avengers series consists of four films from the past decade: Marvel's The Avengers (2012), Avengers: Age of Ultron (2015), Avengers: Infinity War (2018), and Avengers: Endgame (2019). All of these films are ranked within the top ten highest grossing films of all time, with Avengers: Age of Ultron (2015) in 10th, Marvel's The Avengers (2012) in 8th, Avengers: Infinity War (2018) in 5th, and Avengers: Endgame (2019) being the highest grossing film of all time (All Time Worldwide Box Office). Screenplays were found online at Fandom.com and were read and revised as needed while watching each film to ensure accuracy.

\section{Bechdel Test}

The first portion of this study consisted of a directed content analysis of each of the four films mentioned above. Rather than creating a coding process for this step, the three criteria of the Bechdel test were used to examine the portrayal and prominence of female characters - (1) there are at least two speaking female characters, (2) these female characters speak to each other at least once, and (3) they speak about something besides a man (Bechdel, 1986). In order to "pass" the Bechdel test, a film must meet all three criteria - otherwise, it would fail. This binary approach was avoided in order to gain a more nuanced understanding of female representation within the series. Instead, each of the films in the series received a score of $\mathbf{0 , 1 , 2}$, or $\mathbf{3}$ depending on how many of the criteria they met -0 meaning they failed to meet any of the criteria, and 3 meaning they met all three of the criteria. This portion was performed in order to operationalize the representation of women in a simple process as well as examine the way Marvel portrays female relationships.

\section{Same-gender conversations}

To extend beyond the simplicity of the Bechdel test, the second portion of this study involved coding the content of all same-gender conversations. As seen in Zorana Micic's quantitative content analysis of same-sex-interactions in 20 top-grossing films, conversations with multiple genders were not included since this portion is an extension of the Bechdel test, which focuses on interactions between female characters - rather than an analysis of every line of female dialogue (2015).

One person coded all conversations, watching/reading and analyzing each conversation several times to maximize accuracy. Two separate groups were identified: conversations involving strictly female characters and conversations involving strictly male characters. As defined by Hansika Kapoor, a conversation was any verbal exchange between two or more persons, and was assumed to have ended when (a) the setting or the scene changed, with no reference to the earlier conversation; or (b) the topic within the conversation noticeably changed. If the setting or scene changed without a change in characters or topic, however, then it was assumed to be a single, continuous conversation (Kapoor et. al., 2015). If a conversation initially involved only same-gender characters, but eventually included a character of another gender, that conversation was included in the data until that point. A conventional content analysis was performed, meaning that topics or keywords were coded as the films were watched in order for the results to be as holistic as possible. Since the first portion of this study focused so heavily on whether female conversations centered around a man, there were only two preliminary codes formed - (1) for male-to-male conversations, whenever a male character spoke about a woman, and (2) for female-to-female conversations, whenever a female character spoke about a man. The top ten most frequent codes for each gender were then compared to each other. The goal of this portion was to find the specific differences between the portrayal of men and the portrayal of women through film dialogue, focusing on the extent to which their conversations share the same topics and purposes. 


\section{Results}

\section{Bechdel Test}

The Bechdel Test assessed the content of solely female-to-female conversations. There were a total of 22 female conversations throughout the Avengers series.

The first film, Marvel's The Avengers, had 3 named speaking women: Natasha Romanoff, Agent Maria Hill, and Pepper Potts. Because there were at least two named speaking women, the film passed the first criteria of the Bechdel test. However, none of these women ever had a conversation with another woman. There was one female-tofemale conversation, but these characters were unnamed. Furthermore, this conversation centered around a man, since it consisted of a young girl begging a woman to help her sick father, and the woman refused. Since no named female characters spoke to each other, Marvel's The Avengers received a Bechdel score of $\mathbf{1}$.

The second film, Avengers: Age of Ultron had 9 named speaking women: Natasha Romanoff, Wanda Maximoff, Helen Cho, Agent Maria Hill, Laura Barton, Lila Barton, Madame B, Peggy Carter, and Pepper Potts. Since there were at least two named speaking women, it passed the first criteria of the Bechdel Test. A total of 4 female-tofemale conversations were identified, and 1 out of these 4 conversations centered around a man (specific content of these conversations can be found in Coding Results). Because there was at least one female-to-female conversation in this film that did not involve speaking about men, Avengers: Age of Ultron passed the third criteria, receiving a Bechdel score of 3.

The third film, Avengers: Infinity War had 10 named speaking women: Natasha Romanoff, Wanda Maximoff, Gamora, Nebula, Mantis, Okoye, Shuri, Proxima Midnight, Agent Maria Hill, and Pepper Potts. Because there were at least two named speaking women, this film passed the first criteria of the Bechdel Test. A total of 5 femaleto-female conversations were identified, and 3 out of these 5 conversations centered around a man (specific content of these conversations can be found in Coding Results). Since there was at least one female-to-female conversation in this film that did not involve speaking about men, Avengers: Infinity War passed the third criteria, receiving a Bechdel score of 3.

The last film, Avengers: Endgame had 19 named speaking women: Natasha Romanoff, Carol Danvers, Gamora, Nebula, Hope Van Dyne, Valkyrie, Frigga, Mantis, Morgan Stark, Cassie Lang, Laura Barton, Lila Barton, Wanda Maximoff, Okoye, Shuri, Proxima Midnight, Agent Maria Hill, Peggy Carter, and Pepper Potts. Since there were at least two named speaking women, this film passed the first criteria of the Bechdel Test. A total of 12 femaleto-female conversations were identified, and 7 out of these 12 conversations centered around a man (specific content of these conversations can be found in Coding Results). Because there was at least one female-to-female conversation in this film that did not involve speaking about men, Avengers: Endgame passed the third criteria, receiving a Bechdel score of 3.

\section{Coding Results - Male}

There was a total of 344 male-to-male conversations throughout the four films. Marvel's The Avengers had 64 maleto-male conversations, Avengers: Age of Ultron had 83 male-to-male conversations, Avengers: Infinity War had 102 male-to-male conversations, and Avengers: Endgame had 95 male-to-male conversations. With these conversations, a conventional content analysis was performed in order to include as many topics that each gender discussed as possible, so a majority of the codes were created as the films were watched and rewatched. 
Table 1. Number of same-gender conversations.

\begin{tabular}{|c|c|c|}
\hline Movie & Male-to-Male Conversations & Female-to-Female Conversations \\
\hline Marvel's The Avengers (2012) & $64(98.5 \%)$ & $1(1.5 \%)$ \\
\hline Avengers: Age of Ultron (2015) & $83(95.4 \%)$ & $4(4.6 \%)$ \\
\hline Avengers: Infinity War (2018) & $102(95.3 \%)$ & $5(4.7 \%)$ \\
\hline Avengers: Endgame (2019) & $95(88.8 \%)$ & $12(11.2 \%)$ \\
\hline Overall & $344(94 \%)$ & $22(6 \%)$ \\
\hline
\end{tabular}

Table 2. Male Conversations

\begin{tabular}{|c|c|c|}
\hline Code & Frequency* & Definition \\
\hline Sarcasm/jokes & 111 & $\begin{array}{l}\text { Comments about himself or others intended to be humorous } \\
\text { and/or sarcastic }\end{array}$ \\
\hline Giving orders & 78 & Commanding others to perform tasks \\
\hline Worrying about dangers & 60 & $\begin{array}{l}\text { Speaking about possible dangers/conflict that may arise in the } \\
\text { future }\end{array}$ \\
\hline Insulting others & 56 & Degrading or offensive comments to another character \\
\hline Confusion & 42 & $\begin{array}{l}\text { Speaking about having little to no knowledge about a task/con- } \\
\text { flict/danger }\end{array}$ \\
\hline Violence & 36 & Speaking about murder, war, fighting, torture, genocide \\
\hline Preventing conflict & 33 & $\begin{array}{l}\text { Proactively planning against threats, avoiding violence or ten- } \\
\text { sion }\end{array}$ \\
\hline Understanding the Problem & 32 & $\begin{array}{l}\text { Speaking about having deep knowledge about a task/con- } \\
\text { flict/danger }\end{array}$ \\
\hline Helping others & 32 & Offering help or assuring that another character is safe \\
\hline Friendliness & 29 & $\begin{array}{l}\text { Showing kindness towards others by politely greeting, thank- } \\
\text { ing, or speaking about their specific friendship }\end{array}$ \\
\hline \multicolumn{3}{|c|}{$\begin{array}{l}\text { *One conversation can have several } \\
\text { codes }\end{array}$} \\
\hline
\end{tabular}

Since the first portion of this study focused so heavily on whether women talked about men, the only preliminary code formed was whenever a male character spoke about a woman to another male character. Out of 344 male conversations, women were spoken about in 13 conversations. The top 10 most frequent codes that arose in the maleto-male conversations were sarcasm/jokes, giving orders, worrying about dangers, insulting others, confusion, violence, preventing conflict, understanding the problem, helping others, and friendliness (Figure 1). In Figure 1, the code for women is not present; this is because women were the 24th most frequent topic that male characters discussed, and the table only consists of the 10 most frequent codes. For example, in Marvel's The Avengers, women were discussed in one male-to-male conversation, which was when Avengers member Thor worried that Jane Foster, 
his former romantic interest, was in danger after his brother, Loki began capturing people that Thor deeply cared about. On the other hand, the only female-to-female conversation in this film centered around a young girl's sick father, so therefore the entirety of female-to-female conversations in one film centered around the opposite gender. Based on these code frequencies, it is revealed that male characters in these films aren't focused on discussions of women and are more concerned with discussions including sarcasm/joking remarks, danger, maintaining order, and cooperating with other men.

\section{Coding Results - Female}

There was a total of 22 female-to-female conversations throughout the four films. Marvel's The Avengers had 1 female-to-female conversation, Avengers: Age of Ultron had 4 female-to-female conversations, Avengers: Infinity War had 5 female-to-female conversations, and Avengers: Endgame had 12 female-to-female conversations. As stated before, a conventional content analysis was performed with these conversations in order to include as many topics that each gender discussed as possible, so most of the codes were created as the films were watched and rewatched.

Similar to the male analysis, the only preliminary code for female-to-female conversations was whenever a woman spoke about a man to another woman. Out of 22 female-to-female conversations, men were spoken about in 12 conversations. The top 10 most frequent codes that arose in the female-to-female conversations were men, worrying about dangers, violence, insulting others, helping others, family, self-doubt/self-deprecation, threatening others, giving orders, and encouraging others (Figure 2). While men rarely speak with each other about women, the majority of female-to-female conversations mention or center around a man. This implies that the female characters in the Avengers series prioritize discussing men rather than the topics that men most commonly discuss, such as sarcasm/joking remarks, maintaining order, and cooperating with other women. However, besides the most common code, other popular codes found in female-to-female conversations matched those found in male-to-male conversations, with worrying about dangers, violence, and insulting others being discussed at relatively the same rate between the two groups. Therefore, although men are discussed in the majority of the female-to-female conversations in the Avengers series, women are still concerned with several of the same topics as men.

The Bechdel test reveals that female representation has generally improved throughout the series, since the number of female conversations increased along with the number of conversations that did not center around a man. However, the coding results reveal that women are portrayed as highly interested in talking about men, while men are rarely interested in talking about women. While women generally discuss the same topics as men in the series, such as danger and violence, there is still a distinct difference as a result of men being the most frequent topic of discussion among women. Based on these findings, the hypothesis that female-to-female conversations and male-to-male conversations would differ in content is partially supported.

Table 3. Female Conversations

\begin{tabular}{|c|c|c|}
\hline Code & Frequency* & Definition \\
\hline Men & 12 & Speaking about a male character \\
\hline Worrying about dangers & 5 & $\begin{array}{c}\text { Speaking about possible dangers/conflict that may arise in } \\
\text { the future }\end{array}$ \\
\hline Violence & 5 & Speaking about murder, war, fighting, torture, genocide \\
\hline Insulting others & 4 & Degrading or offensive comments to another character \\
\hline Helping others & 4 & Offering help or assuring that another character is safe \\
\hline Family relationships & 3 & Speaking about her own family member \\
\hline Self-doubt/self-deprecation & 3 & Degrading or offensive comments towards herself, feeling \\
unqualified for a task
\end{tabular}




\begin{tabular}{|c|c|c|}
\hline Threatening others & 3 & $\begin{array}{c}\text { Speaking about hurting or killing another character unless } \\
\text { they cooperate }\end{array}$ \\
\hline Giving orders & 3 & Commanding others to perform tasks \\
\hline Encouraging others & 3 & $\begin{array}{c}\text { Attempting to give another character confidence/self- } \\
\text { worth }\end{array}$ \\
\hline * One conversation can have several codes
\end{tabular}

\section{Discussion}

This research aimed to answer the question "Based on the Bechdel test, how does the Avengers series portray women compared to men?" The current study extended beyond the Bechdel test by performing a conventional content analysis of same-gender conversations that examined the differences between the topics discussed by each gender.

The first portion of this study used the Bechdel test to assess the portrayal of women in the four films of the Avengers series. There were very few female-to-female conversations in proportion to the male-to-male conversations; in fact, the first film, Marvel's The Avengers failed to have any conversations between named female characters at all. Male-to-male dialogue dominated the plots of these films, while female-to-female dialogue was sparse. This supports the 2015 study of Micic, which found that out of all conversations in top-grossing films in 2015, 4\% were female-tofemale (Micic, 2015). Furthermore, Anderson and Daniels reported that 75\% of top-grossing films between 1980 and 2016 had majority male dialogue (2016); this is still prevalent in this recent series. According to this agreement with previous work, female representation in dialogue has had little change over time - past studies and the present study (2020) both report a very small amount of female dialogue compared to male dialogue.

This stagnance is not true, however, when considering the individual Avengers films themselves; while female-to-female conversations rarely happened in the series, they increased as each film was released along with the overall number of female characters. Therefore, even though the Avengers series ceased to have equal representation of men and women, female representation has gradually improved as the films continue to be released. This reflects that Marvel Studios has worked to include more women with integral roles in the films. While superhero films still heavily under-represent women, this present study coincides with the beliefs of popular media that Marvel Studios are increasing diversity and representation in gender, as well as race, sexuality, and ability as they release new films (Smith et. al., 2019).

The second portion of this study used a conventional content analysis to specify the topics that each gender discusses and find the differences between female-to-female conversations and male-to-male conversations. It was found that female characters in the Avengers series spoke to each other about men more than any other topic - on the other hand, men rarely spoke to each other about women. By making men a central topic of discussion, the dialogue in these films place an emphasis on male characters, which then cause men to have a crucial role in the films. Since men speak about women so rarely, women are not a central topic of discussion in this film series; this reveals that little to no emphasis is placed on female characters, which portrays the message that women are less crucial to the plot of the film than men.

When considering other codes found in the same-gender conversations throughout the Avengers series, there were both similarities and differences between male-to-male conversations and female-to-female conversations. The most frequently found code in male-to-male conversations was conversations that involved sarcasm or jokes, while, as mentioned before, the most common code for female-to-female conversations was conversations about men women made sarcastic or humorous remarks towards each other very rarely. This trend demonstrates that male characters are much more likely to add humor to the films than female characters. Since women rarely say joking remarks, it reveals that the female characters in the Avengers series are not commonly used as comic relief, while male characters may be seen as more relatable or enjoyable because of their tendency to add comedy and lightness to the series. 
This further supports the idea that male characters are created to be more crucial to the plots of these films than female characters; since male characters dominate the series' comedic dialogue, they are needed to brighten viewers' moods and keep them comfortable when plots become too intense. Female characters rarely have this role in this series, so they are created to be slightly less crucial to the overall plot of these films than men.

As previously discussed, there are substantial differences between the topmost common code for female-tofemale conversations and the top most common code for male-to-male conversations; however, other popular codes among both of the two groups of same-gender conversations reveal that male-to-male conversations and female-tofemale conversations have many aspects in common besides the previously discussed differences. Both male and female characters discussed worries about danger, violence, and insulting remarks of others at relatively the same rate. Since both genders worried about the dangers present in the plots of the films, it can be concluded that female characters are integrated into the central plot to some extent. Although female-to-female conversations were sparse, female characters still spoke to each other about danger and conflict that was relevant to the overall problems within each film and the entire series. This reflects that, according to the Avengers series, men and women are equally capable of identifying a dangerous problem and taking precautions to prevent it from happening. Furthermore, when dangers became unavoidable in the series, both genders reacted equally; female characters discussed violence at the same rate as male characters, which conveys that the women in these films do not shy away from danger, war, or pain, and that they are as capable of handling danger as their male counterparts. This is especially important in the Avengers series since, being a superhero film series, a large amount of screen time is used to show intense fight scenes; therefore, women and men are portrayed as equally prominent in the violence that consumes most of the series' plot. Lastly, male and female characters insulted others relatively equally, which can lead to the conclusion that women are equally capable of defending themselves in a verbal argument as men in these films. While insulting others is not necessarily a positive behavior, this behavior reveals that the female characters in the Avengers series are just as unafraid of others as their male counterparts.

This study adds to literature in gender studies by not only analyzing the amount and qualities of female dialogue, but also analyzing the amount and qualities of male dialogue in order to directly compare both genders' portrayal in the Avengers series. Considering the differences in both the number and specific content of same-gender conversations create a holistic view of how the Avengers series portrays the importance of each gender. Furthermore, the portrayals in these films may potentially be harmful to female viewers. As explained in past studies, women are heavily affected by female portrayals in film - stereotypes on-screen can lead to women believing similar stereotypes about themselves, poor portrayals can lead to poor perceptions of women, and weak female relationships in film can lead to negative attitudes towards female friendships and women in general (Lafky et. al, 1996; Behm-Morawitz \& Mastro, 2008). Taking these findings into consideration, it can be concluded that since female characters frequently discuss men, female viewers may feel pressured to prioritize men in their own lives, even if the Avengers series also showcases female characters that speak of relevant topics.

\section{Limitations}

This study's conclusions were heavily reliant on codes from a conventional content analysis of the Avengers series. While the series was watched several times to enhance accuracy as much as possible, this coding process was performed by only one person. This means that any underlying biases that the researcher didn't notice could not be overlooked or avoided by another perspective. Because of this limitation that can cause a slight miscount of code frequencies, statistical tests that require precise values were avoided, and the only quantitative results taken into account were the rankings of each code for both groups of conversations.

Although the Avengers series contain the most popular films created by Marvel Studios, and while it includes many of the same characters from other Marvel films, these conclusions cannot be completely applied to every film created by Marvel Studios. This is because other Marvel films include more women with larger or even protagonist 
roles, such as Captain Marvel (2019) and the upcoming Black Widow (2020), which reflects that other superheroes films may have more progressive results than this series.

\section{Conclusion and Future Directions}

As previously discussed, this present study developed a unique method that has not been used in order to examine differences in female and male portrayal in the Avengers series. In order to achieve a deeper understanding of overall female portrayal compared to male portrayal in film, future research can utilize this method in larger film samples with multiple genres, rather than just one superhero series. In regard to superhero films, an analysis of all Marvel films, or even films from other superhero franchises, should be conducted in the future in order to find whether other films within the genre continue the same trends as this sample. This will add to the findings of this present study since it can determine whether female protagonists in superhero films are also highly concerned with men, as there is no single protagonist in the Avengers series. Furthermore, this method can be used in other forms of media, such as novels or comic books, to examine whether characters in other forms of media have the same dialogue trends as characters in films. Because poor female portrayals in media can damage women's self-image, it is crucial to continue research on recent media to ensure that portrayals are improving (Lafky et. al, 1996; Behm-Morawitz \& Mastro 2008). Research in film and gender studies helps enlighten filmmakers on the impact their portrayals have on everyday lives; this present study illustrates that Marvel Studios is improving in their female portrayals, but more work must be done to ensure that women do not feel pressured to frequently discuss or prioritize men, which is greatly present in the Avengers series. Ultimately, film companies must reflect that women are viewed as equals to their male counterparts on and off screen.

\section{Acknowledgements}

I can't express enough thanks for my teacher and mentor, Mr. Olivo, for guiding me through the deeply challenging, yet exciting nature of the AP Capstone courses - even as we shifted to the virtual setting of the past year, his support and guidance never fell short. I am also deeply grateful for all of my peers in AP Capstone who were always open to provide help with this project, whether it be detailed criticism or a reassuring high-five. I could not have accomplished this project without their wit and kindness. Lastly, this project would not be possible without all of the women before me who have already developed such a rich discussion of feminism within film. To all of the groundbreaking female scholars, researchers, filmmakers, directors, and artists, I give my deepest thanks.

\section{References}

Agarwal, A., Zheng, J., Kamath, S., Balasubramanian, S., \& Dey, S. A. (2015, June 5). Key female characters in film have more to talk about besides men: Automating the Bechdel test. Association for Computational Linguistics, 830-840. https://www.aclweb.org/anthology/N15-1084

All Time Worldwide Box Office. The Numbers. https://www.the-numbers.com/box-office-records/worldwide/all-movies/cumulative/all-time

Álvarez-Hernández, C., González de Garay-Domínguez, B., \& Frutos-Esteban, F. J. (2015)

Gender representation in contemporary Spanish teen films (2009-2014). Revista Latina de Comunicación Social, 70, 934-960. DOI: 10.4185/RLCS-2015-1079en 
Anderson, H \& Daniels, Matt. (2016, April). The largest analysis of film dialogue by gender, ever. The Pudding. https://pudding.cool/2017/03/film-dialogue/

Avengers: Age of Ultron. Fandom.

https://transcripts.fandom.com/wiki/Avengers: Age of Ultron

Avengers: Endgame. Fandom. https://transcripts.fandom.com/wiki/Avengers: Endgame

Avengers: Infinity War. Fandom. https://transcripts.fandom.com/wiki/Avengers: Infinity War

Bechdel, A. (1986, October 1). The Rule. Dykes to Watch Out For (p. 22). Firebrand Books.

Behm-Morawitz, E. \& Mastro, D. E. (2008, March 1). Mean Girls? The influence of gender portrayals in teen movies on emerging adults' gender-based attitudes and beliefs. Journalism \& Mass Communication Quarterly, 85(1), 131-146. DOI: 10.1177/107769900808500109

Berkman, S., Garland, S., \& VanSteinberg, A. (2017). Quantified feminism and the Bechdel test. Rhodes Information Initiative at Duke, https://bigdata.duke.edu/projects/quantified-feminism-and-bechdel-test

Boden, A. \& Fleck, R. (Directors). (2019). Captain Marvel. Marvel Studios.

Gerard, M \& Poepsel, M. (2018). Black Widow: Female representation in the Marvel Cinematic Universe. Polymath: An Interdisciplinary Arts and Sciences Journal, 8(2), 27-53. https://ojcs.siue.edu/ojs/index.php/polymath/article/view/3314

Heyde, P. (2007). Archive Spotlight: The image of black women in film advertising as seen in the BFC/A's Hatch-Billops collection. Black Camera, 22(1), 13-14. www.jstor.org/stable/27761686

Johnson, C. M. (2015, May). How women of color are portrayed on the cover of magazines: A content analysis of the images Black/African, Latina, Asian and Native American (BALANA). Cornerstone: A Collection of Scholarly and Creative Works for Minnesota State University, Mankato. https://cornerstone.lib.mnsu.edu/etds/438/

Kapoor, H., Bhuptani, P. H., \& Agneswaran, A. (2015). The Bechdel in India: Gendered depictions in contemporary Hindi cinema. Journal of Gender Studies, 26(2), 212-226. doi: $\underline{10.1080 / 09589236.2015 .1102128}$

Lafky, S., Duffy, M., Steinmaus, M., \& Berkowitz, D. (1996). Looking through gendered lenses: Female stereotyping in advertisements and gender role expectations. Journalism \& Mass Communication Quarterly, 73(2), 379-388. doi: 10.1177/107769909607300209

Lauzen, M. M. (2019, February 19). It's a man's (celluloid) world: Portrayals of female characters in the top grossing films of 2019. Center for the Study of Women in Television and Film. https://womenintvfilm.sdsu.edu/uploads/Its a Mans Celluloid World Report 
Micic, Z. (2015). Female interactions on film - Beyond the Bechdel test: A quantitative content analysis of same-sex-interactions of top 20 box office films (Dissertation). http://urn.kb.se/resolve?urn=urn:nbn:se:su:diva-118209

O'Meara, R. (2017). Sexism from page to screen: How Hollywood screenplays inscribe sexism. Networking Knowledge: Journal of the MeCCSA Postgraduate Network, 10 (2), 79-92. http://hdl.handle.net/11343/194843

Pennell, H. and Behm-Morawitz, E. (2015). The empowering (super) heroine? The effects of sexualized female characters in superhero films on women. Sex Roles, 72, 211-220. https://doi.org/10.1007/s11199$\underline{015-0455-3}$

Russo, J. \& Russo, A. (Directors). (2018). Avengers: Infinity War. Marvel Studios.

Russo, J. \& Russo, A. (Directors). (2019). Avengers: Endgame. Marvel Studios.

Schofield, A. \& and Mehr, L. (2016, June 1). Gender-distinguishing features in film dialogue. Association for Computational Linguistics, https://aclweb.org/anthology/W16-0204

Shortland, C. (Director). (2020). Black Widow. Marvel Studios.

Smith, N. (2019, July 22). Marvel phase 4: A new era for diversity in Hollywood? https://www.bbc.com/news/entertainment-arts-49070232

Smith, S. L., Choueiti, M., Scofield, E., \& Pieper, K. (2013). Gender inequality in 500 popular films: Examining on-screen portrayals and behind the scenes employment patterns in motion pictures released between 2007 and 2012. Media, Diversity, and Social Change Initiative: Annenberg School for Communication and Journalism, USC. https://annenberg.usc.edu/sites/default/files/MDSCI Gender Inequality in 500 Popular Films Smith 2013.pdf

The Avengers. Fandom. https://transcripts.fandom.com/wiki/The Avengers

Thomas, A. (2017, January 12). Women only said 27\% of the words in 2016's biggest movies. Medium.https://medium.com/free-code-camp/women-only-said-27-of-the-words-in-2016s-biggest-movies955cb480c3c4

Whedon, J. (Director). (2012). Marvel's The Avengers. Marvel Studios.

Whedon, J. (Director). (2015). Avengers: Age of Ultron. Marvel Studios.

Women's Media Center. (2018, October). SuperPowering girls: Female representation in the sci-fi/superhero genre. Women's Media Center, http://www.womensmediacenter.com/assets/site/reports/bbca-wmcsuperpowering-girls-infographic/Superpowering Gilrs BBCA Womens Media Center.pdf 